\title{
Surveying of Pesticides Commonly on the Markets of Iran in 2009
}

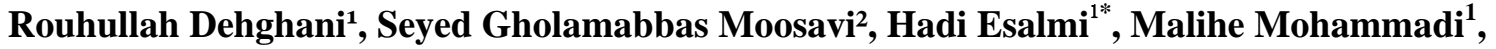 \\ Zahra Jalali $^{1}$, Nargess Zamini ${ }^{1}$
}

${ }^{1}$ Department of Environment Health, Kashan Medical Sciences University, Kashan, Iran; ${ }^{2}$ Department of General Health of Kashan Medical Sciences University, Kashan Medical Sciences University, Kashan, Iran.

Email: *hadieslami1986@yahoo.com

Received July $11^{\text {th }}$, 2011; revised August $15^{\text {th }}$, 2011; accepted September 23 $3^{\text {rd }}, 2011$.

\begin{abstract}
Considering the potential pesticide side effects on environment, their short and long term untoward effects on living creatures, their excessive usage for producing more agricultural products, and also their application to destroy pests of any sort, the present study was carried out to investigate the used amount of common pesticides in Iran markets. A questionnaire was designed. Referring to pesticide selling shops and plants preservations organizations in Tehran and Isfahan, the sufficient data was collected and then categorized regarding the applications and the total amount of used pesticides in a year. The results demonstrated that there were 60 sorts of used pesticides in Iran. They included Organochlorine (10\%), Organophosphorus (28.4\%), Pyrethroids derivatives (10\%), Carbamate derivatives (10\%), and others (41.6\%). The commonest pesticide used in a year was Organophosphorus and the least one was Organochlorine. The obtained data pointed out that the most common pesticide was Organophosphorus. Given that Organophosphorine compounds are poisonous in living creatures and cause short and long term side effects. It is recommended that responsible authorities provide the necessary information for the aimed groups in terms of the allowable using amount of pesticides, the protection strategies and the pesticides hazards on users.
\end{abstract}

Keywords: Pesticide, Organophosphorus, Organochlorine, Carbamate, Pyrethroids, Market, Iran

\section{Introduction}

The increasing population necessitates more agricultural products and foodstuffs that consequently need more pesticide usage to destroy any pests [1,2]. The pesticide compounds include Organophosphorus, Organochlorine, Carbamate and Pyrethroid derivatives [3]. They have some side effects on living creatures; e.g. Organophosphorus inhibits cholinesterase activity and it makes CNS functional disturbances. Organochlorine accumulates in living creature bodies and also in food chain. Carbamate derivatives cause genetic mutations and CNS functional disturbances [4].

These pesticides are used widely to improve agricultural production and also to prevent arthropod-borne diseases. But they are used improperly due to the lake of appropriate knowledge about their applications and untoward effects. The excessive usage is harmful to ecosystem and they contaminate soil, surface and underground water resources $[5,6]$. The relevant fulfilled researches have shown that each year 2.5 million tons of pesticides are used in agriculture sector in the world. $50 \%$ of them penetrate to soil, water and other sources and also to the bodies of living creatures [7]. Relevant poisoning in many countries, especially in developing countries is considered the second causes of mortalities after infectious diseases [8,9].

Pesticides cause untoward effects on man in two ways. Firstly, they have direct effects on the health of persons who use them; and secondly, their remnants accumulate in foodstuffs which also produce side effects on man [10]. The side effects include short term ones like abdominal cramps, vertigo, headaches, diplopia, nausea, ocular disturbances and dermatopathies. Long term adverse effects include increased likelihood of respiratory failures, recalling disturbance, depression, nervous defects, prostate cancer, leukemia and infertility. These problems are considered the major health problems in the world [10-12].

The various investigations conducted on farmers in terms of their health status demonstrated that pesticides may increase the likelihood of Parkinson disease [13,14]. 
WHO estimate that 3 million of farmers suffer from severe poisoning caused by pesticides is in developing countries. 18000 of them die and $21 \%$ of foodstuffs have pesticide contamination [7]. There are 2000 - 3000 hospital admissions each year in USA due to acute pesticide poisoning which $50 \%$ children. Another study revealed that $10 \%-20 \%$ of farmers who worked in fields suffered from poisoning [15]. In a study fulfilled by Aghilinejad et al (2008), regarding the influence of pesticides on the health of farmers in 5 provinces of Iran demonstrated that $50 \%$ of farmers were illiterate and they had been working for 16 - 28 years. Moreover, the data showed that Organophosphorus usage was higher (95\%) in Rafsanjan and Savojbolagh than in other parts of Iran. 68\% of studies farmers used no protection devices and only $5 \%$ were aware of the information pointed on the label of pesticide containers. 55\% of farmers discarded the containers in environment with no special care [16].

With taking into account the potential hazards caused by Pesticides and the excessive usage, the current study was fulfilled to investigate the total amount of used pesticides in Iran in 2009. The obtained results can be used by health care providers, agriculture organizations, and those involved in applying the pesticide so that they will provide appropriate regulations for the safe usage of pesticides.

\section{Materials and Methods}

This was a descriptive study to investigate the common pesticides sold in Iran markets. Firstly, a questionnaire was designed and in included some parameters like the sort of pesticides sold in Iran markets, the total used amount and their applications. The necessary information was obtained with referring to the centers selling pesticides and also to plants preservation organization in Tehran and Isfahan. Secondly, the pesticides were evaluated and categorized concerning their ingredients, their use base on agriculture, public health and animal farm, their applications and the total used amount. The questionnaire was completed and the data was categorized. Quantity of any groups pesticide sold out, were calcu- lated. After that tables were plotted and results were shown in those.

\section{Results}

Totally, 48 pesticides selling shops and 2 plants preservation organizations were questioned. The investigations showed that there were 60 sorts of pesticides in various agriculture and health sectors. They included organophosphorus (28.45), organochlorine (10\%), Pyrethroids (10\%), Carbamat(10\%) and other derivatives(41.6\%) (Table 1). Out of total amount of used Pesticides in a year, 43.65 Insecticides, 12.9\% Acaricides, 17.7\% Herbicides, $12.9 \%$ Fungicides, 1.6\% Molluscicides and 11.1\% Rodenticides were used.

The total amount of used pesticides in liquid from in a year was 206135 liters out of which59.435 was Organophosphorus, $0.11 \%$ Organochlorine, 22.45\% Pyrethroid, $1.26 \%$ crbamat derivatives and $16.75 \%$ other compounds. The total amont of used solid pesticides was $19390 \mathrm{~kg}$ out of which $18.1 \%$ were Organophosphorus, $1.4 \%$ Organochlorine, 9.28\% Pyrethroid, 7.48\% Cabamate derivative's and $63.74 \%$ 0ther sorts. Totally, the highest amount of used pesticides belonged to Organophosphorus and the least one to Organochlorine (Table 2).

Out of total amount of used pesticides regarding to the range of hazards, there were highly (9.3\%), moderately (58.5\%) and lowly (32.2\%) hazardous pesticides. The total amount of used pesticides based on Kilograms, there were $19.2 \%$ highly, $27.9 \%$ moderately and $52.9 \%$ lowly hazardous ones (Table 3).

\section{Discussion}

The obtained data revealed that the most common used pesticide was Organophosphorus. In the study conducted by Bradman et al., (2011) on children inhibitanted near the fields where they world exposure to Organophosphorus pesticides demonstrated that the children consumed foodstuffs containing pesticides. Therefore, in order to prevent the side effects related to pesticides, it is recommended that the persons exposing to foodstuffs contaminated with pesticides wash them thoroughly with

Table 1. The prevalence distribution of common pesticides sold in Iran markets based on their sorts and applications.

\begin{tabular}{|c|c|c|c|c|c|c|c|}
\hline \multirow{2}{*}{$\begin{array}{c}\text { Pesticide groups } \\
\text { Organophosphorus }\end{array}$} & \multicolumn{7}{|c|}{ Applications } \\
\hline & Insecticide & Acaricide & Herbicide & Fungicide & Molluscicide & Rodenticide & Sum (Percent) \\
\hline Organochlorine & 5 & 1 & 1 & - & - & - & $6(10)$ \\
\hline Pyrethroids & 14 & 2 & 1 & 1 & - & - & $17(28.4)$ \\
\hline Carbamate & 5 & 1 & - & - & - & - & $6(10)$ \\
\hline Other derivatives & 2 & - & - & 4 & - & - & $6(10)$ \\
\hline Organophosphorus & 1 & 4 & 9 & 3 & 1 & 7 & $25(41.6)$ \\
\hline Total & 27 & 8 & 11 & 7 & 1 & 7 & $60(100)$ \\
\hline
\end{tabular}


Table 2. The prevalence distribution of sold pesticides in Iran markets according to the used amount per a year.

\begin{tabular}{cccccc}
\hline \multirow{2}{*}{ row } & Pesticide groups & \multicolumn{2}{c}{ Used amount per a year by like solid } & \multicolumn{2}{c}{ Used amount per a year by like liquid } \\
\cline { 3 - 5 } & & $\mathrm{kg}$ & Percent & liter & Percent \\
\hline 1 & Organophosphorus & 270 & 1.4 & 225 & 0.11 \\
2 & Organochlorine & 3510 & 18.1 & 122500 & 59.43 \\
3 & Pyrethroid & 1800 & 9.28 & 46280 & 22.45 \\
4 & Carbamat & 1450 & 7.48 & 2600 & 1.26 \\
5 & Other derivatives & 12360 & 63.74 & 34530 & 16.75 \\
& sum & 19390 & 100 & 206135 & 100 \\
\hline
\end{tabular}

Table 3. The prevalence distribution of used pesticides regarding EPA classification regarding their hazards.

\begin{tabular}{ccccc}
\hline \multirow{2}{*}{ Danger groups } & \multicolumn{2}{c}{ Used amount per a year by like solid } & \multicolumn{2}{c}{ Used amount per a year by like liquid } \\
\cline { 2 - 5 } & $\mathrm{kg}$ & Percent & liter & Percent \\
\hline I & 3720 & 19.2 & 19175 & 6.3 \\
II & 5410 & 27.9 & 120630 & 58.5 \\
III & 1026 & 52.9 & 66330 & 32.2 \\
\hline
\end{tabular}

sufficient water before eating [17]. In a study fulfill by Aghilinegad et al (2008), it was revealed that the most common used pesticide in Rafsanjan and Savojbolagh was Organophosphorus (95\%) [16]. Another investigation performed by Mahmoodi et al (2006) on admitted patients to a hospital in Khoramabadi, Iran, showed that $77.1 \%$ and $22.9 \%$ of poisoning cases owed to Organophosphorus and Organochlorine; respectively [18]. Hence the findings were compatible with ours which showed the main cause of poisoning belonged to Organophosphorus. It seems that Organophosphorus be used mostly due to its wide efficacy and low price in compared with other compounds [19]. Organophosphorus inhibits cholinesterase activity and cause CNS dysfunctions which are life threatening. The highest mortalities due to pesticides belonged to Organophosphorus pesticides [1].

The present study demonstrated that the used amount of Pyrethroid and Carbamate derivatives was lesser than the amount of other compounds due to their high price, the lack of awareness about their applications and the pest resistance, in spite of the fact that they have lesser harmful impact on environment and man in compares with other compounds. In current study, the least pesticide usage belonged to Organochlorine, because the usage belonged to was resistance in various species. As mentioned before, one of the most important obstacles in pesticide application is resistance phenomenon.

One of the most important pests in environmental health is Cockroaches. In the study conducted by Ladoni (1993) in Iran, the resistance level in German Cockroache strains existed in 5 different hospitals to several pesticides like Pyrethroid derivatives; e.g. Permethrin was investigated. The researchers found that some spe- cies were resistant to Permethrin and Cypermethrin [20]. Limooi et al, studied the resistance level in German Cockroache strains to Pyrethroid derivatives and DDT, and the highest resistance levels belonged to Permethrin , Cypermethrin and Cyfluthrin; respectively. Also, German cockroaches had resistance to DDT [21]. Another research conducted concerning the resistance level in American cockroaches to several pesticides in Kashan hospital revealed that these Cockroaches had resistance to Pyrethroids, Permethrin and Cyfluthrin [22].

Therefore, considering long time resistance to pesticides, we should care about the efficacy of pesticides in each species and should carry out specific tests to determine the appropriate pesticide in order to prevent the excessive usage. Given that the relevant poisoning to pesticide in developing countries is 13 times higher than that existed in developed countries; i.e. $85 \%$ of produced pesticides are used in developing countries [10]. It is imperative that definite regulations be implemented regarding the pesticide applications and also placing farmers under an obligation to follow this regulation for preventing poisoning. Another strategy for decreasing pesticides excessive usage is integrated pest management (IPM) [23].

\section{Conclussions}

Considering the excessive pesticides usage, the responsible authorities should supervise the used amount of pesticides. Moreover, continuous education programs should be held for pesticides producers and farmers. It is necessary to broad cast special and technical advertisements in mass media in order to increase the public knowledge concerning the pesticides on toward effects. Hence it is 
recommended that the complete educational series be provided for farmers in four sections: A- terms of how to apply pesticides. B- to manage the short and long term adverse effects .C- to use personal masks while applying pesticides in the fields. D- To discard the pesticides containers carefully. Also the responsible authorities should provide proper information about pesticides for someone involved in applying those.

\section{REFERENCES}

[1] H. Khazaei, N. Korasani, K. H. Talebijahromi, "Surveying the Quality and Health Status of Mazandaran Groundwater due to Use of Diazinon Insecticide (Case Study: Mahmoudabad City),” 12th Environmental Health Conference, Tehran, Iran, 2010, pp. 807-815.

[2] A. Arjmandi, M. Tavakol and M. Shayeghi, "Determination of Organoposporus Insecticide Residues in the Rice Paddies," International Environmental science \& Technology, Vol. 7, No. 2, 2010, pp.175-82.

[3] M. T. Samadi, M. Khodadadi, A. R. Rahmani, A. Allahresani and M. H. Saghi, "Comparison of the Efficiency of Simiultaneous Application of $\mathrm{UV} / \mathrm{O}_{3}$ for the Removal of Organophosphorus and Carbamat Pesticides in Aqueous," Water and wastewater Jornal, in Persian, Vol. 1, 2009, pp. 69-75.

[4] M. Khodadadi, M. T. Samadi, A. R. Rahmani, R. Maleki, A. Allahresani and R. Shahidi, "Determination of Organophosphorous and Carbamat Pesticides Residue in Drinking Water Resources of Hamadan in 2007,” Iranian Journal of Health \& Environmental, in Persian, Vol. 2, No. 4, 2010, pp.250-257.

[5] WHO, "Safe use of Pesticides," Twentieth Report of the WHO Expert Committee on Insecticides, Geneva, 1973.

[6] A. K. Srivastava, D. Mishra, S. Shrivastava, S. K. Srivastav and A. A. Srivastav, "Accute Toxicity and Behavioural Responses Hetropneustes Fossilis to an Organophosphate Insecticides Dimethoate," International Journal of Pharma and Bio Sciences, Vol. 1, No. 4, 2010, pp. 359-363.

[7] G. V. R. Rao, K. l. Sahrawat, C. S. Rao, B. Das, K.K. Reddy, B. S. Bharath, et al., "Insecticide Residues in Vegetable Crops Grown in Kothapalli Watershed Andra Pradesh India,” Indian Journal of Dryland Agricclture \& Development, Vol. 24, No. 2, 2009, pp. 21-27.

[8] A. Farshad, "Survying the Organochlorine and Organophosphorous Poisons in Farms upon Cucumber Pruduct in Fruit and Vegetables Area if Tehran and Health Effects Assessment," Gonabad University of Medical Science, in Persian, Vol. 6, No. 2, 2000, pp. 50-58.

[9] M. S. Yazgan and A. Tanik, "A New Approach for Calculating the Relative Risk Level of Pesticides," Environment International Journal, Vol. 31, pp. 687-692.

[10] S. Ghasemi and E. Karam, "Attitudes and Behaviors about Pesticides Use among Greenhouse Workers in Fars Province,” Journal of Economics and Agricultural Development, in Persian, Vol. 23, No. 1, 2009, pp. 28-40.
[11] F. Konradsen, R. Pieris, M. Weerasinghe, V. Wanderhoek, M. Eddeleston and A. H. Dawson, "Community Uptake of Safe Storage Boxes to Reduce Self-Poisoning from Pesticides in Rural Sri Lanka,” BMC Public Health, Vol. 7, No. 13, 2007, pp. 1-7.

[12] P .Lebailly, V. Bouchart, I. Balidi, Y. Lecluse, N. Heutte, A. Gislard, et al., "Exposure to Pesticide in Open-Field Farming in France,” The Annals of Occpational Hygiene, Vol. 53, No. 1, 2009, pp. 69-81. doi:10.1093/annhyg/men072

[13] F. Kamel, C. M. Tanner, D. M. Umbach, J. A. Hoppin, M. C. Alavanja, A. Blair, et al., " Pesticide Exposure and Self-Reported Parkinsons Disease in the Agricultural Health Study," American Journal of Epidemiology, Vol. 165, No. 4, 2006, pp. 364-374. doi:10.1093/aje/kwk024

[14] J. A. Firestone, T. S. Weller, G. Franklin, P. Swanson, T. Longstreth and H. Chckoway, "Pesticides and Risk of Parkinson Disease,” American Medical Association, Vol. 62, 2005, pp. 91-95.

[15] R. Dehghani, “Environmental Toxicology,” Kashan University of Medical Science and Takderakht Publisher, Kashan, 2010.

[16] M. Aghilinegad, S. Mohamadi, A. S. farshad, "Effecting the Pesticides Consumption upon Agricultural Health,” Journal Research of Shahid Beheshti University of Medical Science, in Persian, Vol. 31, No. 4, 2008, pp. 327-331.

[17] A. Bradman, R. Castorina, D. Boydbar, J. Chevrier, M. E. Harnly, E. A. Eisen, et al., "Determinants of Organophosphorus Pesticide Urinary Metabolite Levels in Young Children Living in an Agricultural Community," International Journal of Environmental Research and Public Health, Vol. 8, 2011, pp. 1061-1083. doi:10.3390/ijerph8041061

[18] G. A. Mahmodi and R. Asaei, "Epidemiological Surveying the Pesticide Poisoning Cases (Organophosphorus and Organochlorine) in Patients Admitted at Hospitals in Khorram Abad Martyrs Nomads in First Xix Months in 2006,” Yafte Journal in Lorestan University of Medical Sciences, in Persian, Vol. 10, No. 1, 2008, pp. 3-10.

[19] M. Shayeghi, M. Khobdel, F. Bagheri and M. Abtai, "Azynphosmethyl and Diazinon Residues in Qarasu River and Gorganrood in Golestan Province," Journal of Public Health and Health Research Institute, in Persian, Vol. 6, No. 1, 2008, pp. 75-82.

[20] H. Ladonni, "Susceptibility of Blattella Germanica to Different Insecticides in Different Hospitals in TehranIran,” Journal of Entomology Society of Iran, in Persian, Vol. 12, No. 13, 1993, pp. 23-28.

[21] M. Limoee, H. Ladonni, A. A. Enayati, H. Vatandoost and M. Aboulhasni, "Detectionof Pyrethroid Resistance and Cross-Resitance to DDT in Seven Field-Collected Strains of the German Cockroach Blattella Germanica (L.) (Dictyoptera: Blattellidae)," Journal of Biological Sciences, Vol. 6, No. 2, 2006, pp. 382-387. doi:10.3923/jbs.2006.382.387

[22] A. Dorodgar, R. Dehghghani, H. Hooshiar and M. Sayahh, "Sensitivity of American Cockroach in Kashan hospital to insecticides,” Feyz Kashan university Medical 
Sciences \& Health Services, in Persian, Vol. 2, No. 20, 1998, pp. 89-94.

[23] M. G. Calvert, J. Karnik, L. Mehler, J. Beckman, B. Morrissey, J. Sievert, et al., "Acute Pesticide Poisoning among Aggricutural Workers in the United State,” American Journal of Industrial Medecine, Vol. 31, 2008, pp. 883-898. doi:10.1002/ajim.20623 